\title{
EDUCAÇÃO EM DIREITOS HUMANOS: NARRATIVAS EMERGENTES
}

\author{
EDUCATIONINHUMAN RIGHTS: EMERGINGNARRATIVES
}

\author{
Elione Maria Nogueira Diógenes ${ }^{1}$
}

\begin{abstract}
RESUMO
A extensão é considerada um dos tripés de funcionamento das universidades. A ideia é que nos trabalhos desenvolvidos no âmbito acadêmico não ocorra dissociabilidade entre pesquisa, ensino e extensão. Infelizmente, a realidade é outra. Em geral, os professores dedicam-se mais ao ensino e a pesquisa, enquanto a extensão reduzse a uma atividade menor no conjunto da prática científica. O presente texto caminha na perspectiva de demonstrar que é possível articular ensino, pesquisa e extensão de modo a materializar o compromisso social da Academia por meio de projetos que contribuam com a produção e apropriação do conhecimento, efetivando a formação dos acadêmicos de modo que os mesmos assumam a responsabilidade social como princípio de sua vida profissional.
\end{abstract}

Palavras-chave: Extensão. Educação em Direitos Humanos. Responsabilidade Social.

\section{ABSTRACT}

The extension is considered one of the tripods functioning of universities. The idea is that we work within academia does not occur dissociation between research, education and extension. Unfortunately, reality is another. In general, most teachers are dedicated to teaching and research, while the length is reduced to a lower activity in the whole of scientific practice. this text walks the prospect of demonstrating that it is possible to articulate teaching, research and extension in order to materialize the social commitment of the Academy through projects that contribute to the production and appropriation of knowledge, effective the training students so that they assume social responsibility as a principle of his professional life.

Keywords: Extension. Human Rights Education. Social Responsibility.

\section{INTRODUÇÃO}

(...) Precisamente porque sua ação de extensão se dá no domínio do humano e não do natural, o que equivale dizer que a extensão de seus conhecimentos e de suas técnicas se faz aos homens para que possam transformar melhor o mundo em que estão, o conceito de extensão também não tem sentido do ponto de vista humanista. E não de um humanismo abstrato, mas concreto, científico. (FREIRE, 1983, p. 11).

\footnotetext{
${ }^{1}$ Universidade Federal de Alagoas (UFAL). Email: elionend@uol.com.br
} 
O educador pernambucano, Paulo Freire ${ }^{2}$, tem uma obra marcada pelo compromisso com a transformação social, em que o papel da extensão é profundamente trabalhado. Em seu livro “Extensão ou Comunicação? (1983)"o autor discorreu, com propriedade,sobre a questão da extensão. Em sua visão, o vocábulo comunicação é mais apropriado para o tipo de ação que se efetiva para além dos muros da universidade. Neste trabalho, assumimos o termo extensão pela conotação proposta por Freire (1983), pois, do ponto de vista aqui adotado, o que deve motivar a atividade extensionista é o firme propósito de transformar a realidade social bem como manter um compromisso social com a comunidade local aonde se inserem as ações de produção/apropriação do conhecimento.

Neste fio de raciocínio não destoamos do que a própria universidade apreende como extensão, pois esta é uma ação daquela junto à comunidade, favorecendo-a por meio do conhecimento alcançado a partir do ensino e da pesquisa. Tal estratégia reconfigura o ato de conhecer e produz um novo conhecimento a ser sistematicamente trabalhado e retrabalhado com o apoio da própria comunidade. Está na base da extensão à questão dialógica, como tão bem expressa Freire (1983, p. 13), pois “(...) a extensão é educativa” (Com este sentido é que realizamos o projeto que detalhamos melhor nos próximos tópicos).

No Brasil, especialmente, o conceito extensão é tomado enquanto relação imediata dos membros internos de uma dada instituição de nível superior com a sociedade. Aqui, essencialmente a atividade de extensão é o elo que mantém ativo o conhecimento gerado nas instituições de pesquisa com o fim de transformar a realidade social, indo além da formação dos alunos matriculados nessa ou naquela instituição. De fato, a extensão consta como um dos pilares do ensino superior agregado ao ensino e a pesquisa do modo como dispõe o artigo 207, caput, da Constituição Federal de 1988.

Especificamente, na Universidade Federal de Alagoas a extensão tem um papel bastante importante por dois motivos: 1) o bairro onde se localiza a UFAL é uma área de periferia em que a pobreza é marca permanente devido principalmente ao seu não enfrentamento (SILVA, 2001) ${ }^{3}$; 2) o Estado de Alagoas possui o menor Índice de Desenvolvimento Humano Municipal (IDHM) do Brasil, segundo pesquisa do Programa das Nações Unidas para o Desenvolvimento (PNUD/2013), que leva em consideração os critérios de renda, longevidade e educação, a saber, média de $0,631^{4}$. A função social da UFAL tornase ainda mais politicamente necessária nesse contexto. 
O próprio Estatuto da UFAL reconhece a importância das ações de extensão no sentido de contribuir com o desenvolvimento social e minimizar as mazelas sociais em que vive grande parte de sua população (ALAGOAS. UFAL, ESTATUTO DA UFAL, 2006) 5 .

Por conta disso a UFAL, por meio da Pró-Reitoria de Extensão, busca fortalecer o pilar "extensão" financiando projetos que tenham nítido comprometimento com as questões sociais. Nisto: "A universidade e, em especial, as pró-reitorias de extensão devem induzir programas e projetos que visem enfrentar os problemas específicos produzidos pela situação de exclusão." (NOGUEIRA, 2000, p. 63); agindo assim é possível - quem sabe - minimizar os efeitos perversos da globalização excludente (CHESNAIS, 1996)?

Em tal sentido, no ano de 2011 submetemos a referida Pró-Reitoria um projeto intitulado "Formação Continuada em Direitos Humanos para Professores do Ensino Médio", que teve como objetivo trabalhar com a questão da educação em direitos humanos com as alunas do curso de Pedagogia e com os professores da educação básica da escola pública de Maceió. Com a aprovação do referido projeto iniciamos os trabalhos com a colaboração de um bolsista (ação afirmativa), aluno do curso de Pedagogia.

A preocupação dizia respeito a identificar como as escolas públicas de Ensino Médio em Maceió tratavam o tema dos Direitos Humanos nas salas de aula. Portanto, interessou-nos a relação entre os Direitos Humanos e a educação. Deste modo, estudamos a construção histórica dos Direitos Humanos no Brasil e seu arcabouço conceitual.

Metodologicamente, além da reconstrução histórica e conceitual da temática trabalhamos com os Parâmetros Curriculares Nacionais para o Ensino Médio lançados em 1999 pelo Ministério da Educação em que os Direitos Humanos figura como tema transversal. Igualmente fizemos uso do Plano Nacional de Educação em Direitos Humanos (2006) e das Diretrizes Nacionais para a Educação em Direitos Humanos (2012).

Realizamos tais estudos à luz da análise freireana em que o homem “(...) não pode ser compreendido fora de suas relações com o mundo, de vez que é um "ser em situação", é também um ser do trabalho e da transformação do mundo. O homem é um ser da "práxis"; da ação e da reflexão.” (FREIRE, 1983, p. 6). Assim, encetamos o presente estudo e aqui apresentamos os resultados. 


\section{DESENVOLVIMENTO DO PROJETO}

Aqui o homem vê o que deus não saberia ver. (BALZAC, 2010, p. 307).

A temática dos Direitos Humanos no Brasil entrou na agenda das discussões coletivas precisamente com a redemocratização (últimas décadas do século $\mathrm{XX}$ em diante). A sistemática de abusos cometidos pelas autoridades no período da Ditadura Militar (1964/1985) foi denunciada pelas entidades de luta e organização popular com o amplo apoio da Igreja Católica, que na época teve vários de seus padres e colaboradores presos e torturados.

De lá para cá, a pauta dos Direitos Humanos tem se fortalecido configurando-se, inclusive como política pública defendida por amplos setores da sociedade civil organizada e outros segmentos e organizações não governamentais. Retrata tal conjuntura sociopolítica, a Constituição de 1988, em que o Estado Democrático de Direito acolhe e prescreve os direitos humanos como artefato complementar do arcabouço jurídico e institucional do país, das políticas públicas e da prática cultural democrática, transformando a educação em direitos humanos o ponto principal da política de Estado e chave de acesso de sociabilidade humana.

Posto isto: no ano de 2003, é lançado pelo Comitê Nacional de Educação em Direitos Humanos, o Plano Nacional de Educação em Direitos Humanos que tem como objetivo “contribuir para a vigência de um Estado Brasileiro realmente democrático, embasado em uma proposta de governo que prioriza as políticas públicas em busca da melhoria das condições de vida da população" (BRASIL, PNEDH, 2003, p. 11). Para o PNEDH:

Principalmente no que se refere aos direitos humanos, entendidos como os direitos de todo ser humano, sem distinção de raça, nacionalidade, etnia, gênero, classe social, cultura, religião, opção sexual, opção política, ou qualquer outra forma de discriminação. São os direitos decorrentes da dignidade do ser humano, abrangendo, dentre outros: os direitos à vida com qualidade, à saúde, à educação, à moradia, ao lazer, ao meio ambiente saudável, ao saneamento básico, à segurança, ao trabalho e à diversidade cultural. (idem, p. 10). 
Nesse cenário, há uma parte no PNEDH dedicado ao Ensino Médio, que após a reforma implantada pelo Ministério da Educação (MEC), em meados da década de 1990 do século XX, passou a ter uma nova função social, qual seja:

Aprender para a vida. Esta é a filosofia básica da reforma do Ensino Médio que o Ministério da Educação (MEC) vem implementando no País. A reforma começou com a aprovação da Lei de Diretrizes e Bases da Educação Nacional (LDB), em 1996. Um dos pontos principais da reforma é a separação da Educação Profissional do ensino regular. A partir de agora, a formação técnica é um complemento da Educação geral e não um pedaço dela. Com essa mudança, o ensino profissional pode ser cursado ao mesmo tempo que o Ensino Médio, mas o aluno tem que fazer os dois cursos para receber o diploma.(Folha de S. Paulo, 19/8/99).

A nova Lei de Diretrizes e Bases da Educação nacional (LDBEN) n ${ }^{0}$ 9394/96 no seu Art. Artigo 35, I e II, assegura que as finalidades do ensino médio são a "consolidação e o aprofundamento dos conhecimentos adquiridos no ensino fundamental, possibilitando o prosseguimento de estudos" e a "preparação básica para o trabalho e a cidadania do educando para continuar aprendendo, de modo a ser capaz de se adaptar com flexibilidade a novas condições de ocupação ou aperfeiçoamento posteriores".

Delineado esse novo contexto, as propostas pedagógicas das escolas e os currículos constantes dessas propostas incluirão competências básicas, conteúdos e formas de tratamento dos conteúdos, previstas pelas finalidades do ensino médio estabelecidas pela lei. O "aprender para a vida" insere nos quatro pilares da educação definidos por Delors (2004), ou seja, a prática pedagógica desenvolver-se-á por meio de quatro aprendizagens fundamentais, a saber: aprender a conhecer,aprender a fazer, aprender a conviver e aprender a ser. Nos dois últimos insere-se a temática dos direitos humanos aqui abordada.

As mudanças instauradas têm segundo os estudiosos Frigotto (1998) e Krawczyk (2000) relação direta com o processo de reordenamento do Estado contemporâneo, nos quadros da mundialização do capital. Por quanto, o ensino médio brasileiro está inserido no contexto da educação geral reservado à continuidade dos estudos a priori garantida, por Lei, a todos os brasileiros.

Ao analisar a lógica, os consensos e as tensões forjadas no cenário da reforma do "novo ensino médio", colocamos a pergunta central: como formar os estudantes da escola 
média no sentido de torná-los sujeitos e agentes em prol de uma cultura de respeito aos direitos humanos?

É imperioso admitir que não se tenha estudos sobre as características diferenciadas dos estudantes que frequentam a escola média diurna e noturna, bem como entre a escola média urbana e a escola média rural que acabam gerando práticas diferentes de ensino na escola média.

Certo é que o Brasil não é um todo homogêneo, e tanto mais as relações de produção organizem-se com foco na dominação e na exploração desmedida tanto mais temos situação extrema de desrespeito aos Direitos Humanos, como ocorre secularmente no Brasil.

Tinha razão Joaquim Nabuco (1849-1919) quando argumentava que a escravidão permaneceria determinando as relações sociais no Brasil, mesmo após sua abolição em 1888, porque não se realizou a abolição social, apenas concedeu-se aos escravizados uma liberdade de corpo e não de direitos.

Assim sendo, a problemática dos direitos humanos permanece mais atual do que nunca, visto que o problema de essência é o seguinte: há seres humanos que gozam formalmente de direitos, mas que concretamente não têm acesso a esses direitos, por conta disto, são sistematicamente desrespeitados enquanto sujeitos de direitos.

Por força de um pensamento social conservador, discutir essa questão em sala de aula não parece nada fácil. Entretanto, precisamos urgentementeformar os diferentes sujeitos sociais e conscientizá-los quanto ao tema "Direitos Humanos" que é particularmente problemático no Brasil, um país reconhecidamente marcado pelo domínio e opressão colonial e neocolonial desde a sua inserção no mundo ocidentalizado no século XVI. Contudo, fíca a pergunta: o que são direitos humanos?

Segundo Rabenhorst (2010, p. 15) "Na sua origem, a palavra direito significa exatamente aquilo que é reto, correto ou justo". Deste modo, a noção de direito em geral está ligada a uma questão ética e moral, portanto, é um senso de percepção que temos quanto às ações humanas e seu juízo no campo do correto e do incorreto.

Continuando: o mesmo autor nos informa que "o termo "direito" se opõe ao que é torto, avesso ou injusto." (idem). Por isto que, podemos com certeza qualificar uma ação de justa ou injusta conforme sua intenção. 
Ao considerar as peculiaridades históricas e sociais brasileiras e os seus desdobramentos no Nordeste e em especial em Alagoas, queremos com este projeto formar professores do Ensino Médio no sentido de que se tornem competentes e capazes de desenvolverem pedagogicamente essa temática em sala de aula.

É importante atentar para o fato de que tal temática se encontra nos Parâmetros Curriculares Nacionais para o Ensino Médio lançados em 1999 pelo Ministério da Educação (BRASIL, MEC) como tema transversal. Portanto, deve ser abordada em todo o currículo escolar do nível secundário em todas as disciplinas.

Entretanto, isso não ocorre simplesmente porque a escola média ignora tal demanda seja pela precariedade da formação docente nos principais cursos de formação seja porque não há qualquer interesse pedagógico em se abordar tal assunto em sala de aula, vez que as Diretrizes Nacionais para a Educação em Direitos Humanos (2012) no seu Art. $3^{\circ}$ prescreve a “(...) Educação em Direitos Humanos, com a finalidade de promover aeducação para a mudança e a transformação social.”. Os fundamentos, pois, de uma educação voltada aos direitos humanos são:

I - dignidade humana; II - igualdade de direitos; III - reconhecimento e valorização das diferenças e das diversidades; IV - laicidade do Estado; V - democracia na educação; VI - transversalidade, vivência e globalidade; e VII - sustentabilidade socioambiental.

Deste modo, buscamos através do projeto realizar uma ação interventiva dentro da escola na perspectiva de que os professores se conscientizem da necessidade de trabalharem a questão dos direitos humanos com os jovens do ensino médio, vez que eles são em sua grande maioria alijados dessa discussão.

Atender igualmente a cultura juvenil é necessário para realizar um trabalho pedagógico cujo fulcro é a construção de uma consciência cidadã, de respeito aos direitos humanos e a democracia. Com esta visão, efetivamos curso de formação continuada para os docentes do Ensino Médio da rede pública de educação de Alagoas com a certeza de que não se faz sociedade justa sem o respeito aos direitos humanos.

De igual modo, esse projeto almejou interagir com as principais organizações e estabelecimentos de defesa dos Direitos Humanos - centros, sociedades, associações, comissões e conselhos - na sociedade maceioense, de modo que possamos perceber como foi ocorrendo historicamente à luta em defesa dos direitos humanos. 
Conseguimos também uma articulação com os atores sociais e os órgãos de proteção e defesa do cidadão, no sentido de contextualizar as suas atuações contemporâneas assim como travar uma discussão em torno da importância de se inserir os direitos humanos como assunto central nas salas de aula de Ensino Médio.

Em tal sentido, o objetivo geral do presente trabalho foi: Realizar um curso de formação continuada com foco na temática dos Direitos Humanos, cujo público-alvo, os professores do Ensino Médio, sintam-se capazes de abordarem tal temática em sala de aula.

Quanto aos objetivos específicos foram:

1) Instigar o interesse e a participação de estudantes e professores do CEDU no envolvimento de ações científicas de caráter empírico que absorva as comunidades;

2) Impulsionar o comprometimento científico através de ações extensionistas que tenham como fulcro a transformação social;

3) Fornecer elementos formadores de profissionais na área da educação preocupados com a ética e com a proposta política de uma sociedade mais justa;

4) Gerar a formação de grupos para o estudo com foco na metodologia da pesquisaação;

5) Identificar as escolas que ofertam Ensino Médio nas escolas públicas de Maceió;

6) Montar o perfil do professor de Ensino Médio nas escolas públicas de Maceió;

7) Identificar as principais dificuldades encontradas pelos professores na realização de um trabalho pedagógico que insira a temática dos Direitos Humanos nas salas de aula de ensino médio em Maceió;

8) Planejar um curso de formação continuada em Direitos Humanos respeitando os interesses dos professores-alunos;

9) Selecionar duas escolas públicas de Ensino Médio em Maceió para a realização do curso de formação continuada em Direitos Humanos.

No projeto as metas centrais constituíram-se: a) Fazer um levantamento das escolas de Ensino Médio, em Alagoas e em Maceió; b) Construir um diagnóstico acerca da abordagem da temática dos Direitos Humanos nas escolas públicas de Ensino Médio, em Maceió e c) Elaborar propostas pedagógicas para a abordagem da temática dos Direitos Humanos nas escolas públicas de Maceió. 


\section{ARCABOUÇO METODOLÓGICO: material e métodos}

O projeto do qual tratamos foi aprovado pela Pró-Reitoria de Extensão (PROEXT) ligada à UFAL em maio de 2011, quando se iniciou; e, terminou em maio de 2013. O mesmo foi executado por uma professora do CEDU e um aluno bolsista do curso de Pedagogia. Temos firmado recentemente uma parceria com o Núcleo de Direitos Humanos coordenado por uma professora do curso de Serviço Social da UFAL que desenvolve em Alagoas, o Projeto Capacitação de educadores da rede básica de ensino em Educação em Direitos Humanos, cujo objetivo é a

(...) promoção de mudanças no sistema educacional de ensino no sentido de implementar uma cultura de Direitos Humanos nas escolas por meio da capacitação de educadores, técnicos e gestores da rede básica de educação, lideranças comunitárias, profissionais das cinco áreas do Plano Nacional de Educação em Direitos Humanos.

A base metodológica do Projeto foi pensada de duas formas: 1) por meio de entrevistas com os professores e de consulta aos arquivos da Secretaria de Educação e 2) formação continuada dirigida aos professores do ensino médio.

Deste modo, a extensão conecta-se intrinsecamente com a pesquisa. Atuamos junto às instituições promotoras dos Direitos Humanos em Maceió e articulamos sua atuação com os objetivos do projeto. Os Direitos Humanos é uma temática por si instigante. Deste modo, é imprescindível a participação social dos principais envolvidos na temática: organizações e estabelecimentos de defesa dos Direitos Humanos - centros, sociedades, associações,comissões e conselhos. De tal modo, a articulação dialógica permeou todo o trabalho e perfilhamos com Freire apud Chonchol $(1983$, p. 7) que:

(...) conhecer não é o ato através do qual um sujeito transformado em objeto, recebe dócil e passivamente os conteúdos que outro lhe dá ou lhe impõe. $\mathrm{O}$ conhecimento pelo contrário, exige uma presença curiosa do sujeito em face do mundo. Requer sua ação transformadora sobre a realidade.Demanda uma busca constante. Implica invenção e reinvenção. 
O corpo discente que - na verdade - são docentes da educação básica tornou-se imprescindível na execução desse projeto. Assim, o projeto teve como meta sine qua non incentivar a participação dos alunos de modo que os mesmos se sintam atraídos pela temática e a desenvolvam em sua sala de aula com autonomia.

A pesquisa-ação com base nas ideias de Thiollent (2007) foi o nosso guia procedimental. Desde o primeiro momento da realização do projeto até o seu término a pesquisa-ação norteou todo o desenvolvimento das ações. Deste modo, por meio da pesquisaação promovemos a participação de todos os envolvidos no sentido de dar minimamente conta da complexidade do tema.

O importante é que o público-alvo do projeto compreendeu a proposta como um todo, possibilitando a própria flexibilização no campo do planejamento e da execução, tendo em vista que os professores das salas de aula da escola pública selecionada para a operacionalização do projeto estavam também realizando atividades docentes. Daí a necessidade de se “(...) resgatar a dimensão humana do trabalho, transformando-o realmente em um fator de realização pessoal, e não de opressão, repressão e depressão como muitas vezes ocorre." (MARTINELLI, s/d, mimeo).

Proporcionamos aos envolvidos no curso uma rara oportunidade de assumir seus pressupostos e discuti-los com base num entendimento coletivo. De tal maneira, um trabalho como nosso deve propiciar aos professores um entendimento de seus problemas para que eles possam percebê-los e levantar alternativas que vão ao encontro de seus interesses pedagógicos.

\section{RESULTADOS E DISCUSSÃO}

Alagoas é reconhecidamente um estado que tem sérios problemas no que toca a questão educacional voltada para o nível médio de ensino. Conforme Acioli (2003) Alagoas é um estado em “(...) decadente situação econômica (...)” (idem, p. 109).

Com relação ao ensino médio, o Estado enquanto poder público somente assumiu sua função para com o ensino médio a partir da década de 1990 em que teve um crescimento de 
100\% nas matrículas em relação às outras redes: “Apesar do crescimento de 100\%, observa-se que a rede estadual começa a apresentar um crescimento a partir do ano de 1998 (...)” (idem, p. 112).

Segundo o documento de Reestruturação e Expansão do Ensino Médio no Brasil (BRASIL, 2008) a educação média é um direito humano formal essencial para consolidação dos valores e conhecimentos científicos construídos pela humanidade.

Nesse sentido, enfrentamos desafios sérios no desenvolvimento do projeto. Antes de explicitarmos os resultados é importante colocar que o projeto enfrentou resistência por parte dos professores das duas escolas públicas de ensino médio de Maceió/AL.

As unidades escolares onde o projeto foi desenvolvido localizam-se em bairros periféricos de Maceió com problemas de violência, de tráfico de drogas e alto índice de criminalidade juvenil, a saber: Clima Bom e Santos Dumont que têm acoplados, uma população de 61.650 habitantes, conforme dados do Instituto de Brasileiro de Geografia e Estatística (IBGE, 2000).

As escolas atendem alunos e alunas de classe social baixa em sua maioria. Foram entrevistados 12 professores que têm nível superior e podemos perceber que há um preconceito muito grande com relação a essa abordagem na sala de aula. Dos 12 professores entrevistados, $62 \%$ não têm qualquer conhecimento sobre tal temática. $58 \%$ acham desnecessário discutir tal questão, pois favoreceria a marginalidade e 45\% veem com desconfiança tal temática.

A preocupação central de nosso projeto foi a de construir uma cultura favorável aos Direitos Humanos dentro das escolas, vez que essas são espaços de sociabilidade humana, que não raras vezes contribuem para o favorecimento ou não de uma prática pedagógica fundada na valorização da dignidade humana.

Assim causou-nos perplexidade, o fato de muitos professores guardarem ressalvas quanto à temática. É importante deixar claro que os direitos humanos, dizem respeito antes de qualquer coisa à vida e ao direito a ela, de forma plena e saudável. Uma das consequências sobre a falta de conhecimento dos próprios direitos é a impossibilidade de exercer o direito essencial que assinalou Arendt (2008): o direito a ter direitos.

Os dados mostram que para a maior parte dos entrevistados a democracia está reduzida a uma competição eleitoral. A mídia conservadora consegue manipular a 
mentalidade dos professores de forma que não raro se expressam da seguinte forma: direitos humanos é coisa de bandido. Outra resposta interessante: deviam-se ensinar aos alunos os deveres e não os direitos.

Apesar dessa resistência que entendemos ser fruto das distorções que o tema Direitos Humanos sofre na grande mídia compreendemos ser possível continuar com o projeto inclusive alargando-o para outras escolas. Sabemos também que o poder público local não tem contribuído muito para reversão dessa situação, pois há uma crescente dicotomia entre o projeto político pedagógico da Secretaria de Educação e a realidade social do povo alagoano.

Há também uma ausência de políticas públicas voltadas para resolver as problemáticas da miséria e da situação de risco em que vive a grande maioria das crianças e dos adolescentes. Em suma, o nosso projeto tem demonstrado que há muito por fazer e poucos colaboradores. De todo modo, a escola é um espaço geofísico complexo e como tal precisa ser compreendida, pois, quem sabe a partir dela é possível transformar socialmente a dura realidade vivida?

\section{CONCLUSÕES}

Com o projeto "Formação Continuada em Direitos Humanos para Professores do Ensino Médio" sabemos que se fazem necessárias duas abordagens ao longo desse processo. Primeira: implantação de políticas de educação no sentido de formar permanentemente os professores no campo dos Direitos Humanos, tornando essa temática o princípio pedagógico por excelência da ação educativa. Segunda: garantia do direito de todos os cidadãos a uma educação de qualidade seja em qual nível ou essa ou aquela modalidade.

Um amplo processo de garantia de direitos voltados especificamente para o campo educativo, com certeza, reverteria a atual condição de degradação humana a que está submetida considerável parcela da população alagoana. Pode ser utópico acreditar que isso pode ser possível. É que

Os 'fatos', a cada nova abordagem, se apresentam como produtos de relações históricas crescentemente complexas e mediatizadas, podendo ser contextualizadas de modo concreto e inseridos no movimento maior que os engendra. A pesquisa, portanto, procede por aproximações sucessivas ao real, agarrando a história dos processos 
simultaneamente às suas particulares internas. (PAULO NETTO, 2004, p. 58).

Deste modo acreditamos que, antes de tudo o conhecimento é fundamental. E o conhecimento sobre os Direitos Humanos é condição sine qua non para a conscientização em defesa dos mesmos.

Em certo sentido é impossível defender algo que eu não conheço que eu não sei onde e como se origina, que eu não tenho como válido socialmente e constituído como histórico. Daí que os professores entrevistados ao falarem que direitos humanos é coisa de bandido e que as vítimas não têm direitos estão nada menos nada mais que demonstrando desconhecimento de causa e do sentido da causa.

Por isto que a formação continuada aqui se coloca como essencial vez que nos cursos de graduação de professores não se aborda tal questão. De modo que a compreensão dos direitos humanos no tempo e no espaço vai desvelar a verdadeira face desses qual seja: que diz respeito ao estatuto da humanidade, da garantia da vida e do viver, do viver e do amar, do amar e do ser feliz em uma sociedade que sistematicamente atravessa com uma lança os direitos básicos como saúde, trabalho e educação.

O Estado Democrático de Direito no Brasil institucionalizou os Direitos Humanos, pelo menos em Lei. Agora, o que nos cabe? A defesa e a promoção dos mesmos. A vigilância cidadã no sentido de não permitir que se transforme essa conquista em uma conquista neutra, onde apenas subsiste o seu conteúdo em forma de retórica. A nossa prática inicial nesse projeto demonstra que os Direitos Humanos é um desafio porque a realidade nossa é ainda desigual e profundamente aniquiladora dos Direitos Humanos.

Não importa muito para as pessoas no atual contexto de individualismo neoliberal o que ocorre com o outro, pois em geral o outro é visto como um inimigo em potencial, pois é o concorrente de uma vaga, de um ponto comercial, de uma falsa concepção de mérito.

Nesse contexto, as cenas comuns assistidas, de forma assustadora, por todos são a negação dos direitos e o acirramento dos conflitos sociais, raciais e étnicos que provoca uma verdadeira guerra social institucionalizada. É neste quadro que devemos e precisamos lutar pela vida e pelo direito de ter direitos seja em que circunstancia histórica vivamos.

Assim, trata-se de manter-se uma inflexível prevenção no âmbito da cidadania para garantir a defesa e preservação da liberdade humana: essa palavra que o "sonho humano alimenta que não há ninguém que explique e ninguém que não entenda". Entretanto, é a 
liberdade um sonho? É a liberdade um fetiche? É a liberdade uma abstração? Pode ser que sim e acreditamos nisso, mais do que isto o ser humano almeja a liberdade para dela fazer sua bandeira em prol da dignidade humana que só será plenamente efetivada quando, enfim, os direitos humanos forem uma realidade universal.

Ainda como conclusão tem-se o fato de que legalmente todo o currículo escolar do nível secundário deveria abordar os Direitos Humanos em todas as disciplinas e não como assunto isolado. Entretanto, isso não ocorre simplesmente porque a escola média ignora tal demanda seja pela precariedade da formação docente nos principais cursos de formação seja porque não há qualquer interesse pedagógico em se abordar tal assunto em sala de aula.

Notas:

1 - Este texto é fruto de um projeto de pesquisa-ação desenvolvido no curso de Pedagogia da Universidade Federal de Alagoas durante dois anos (2011 e 2012). O projeto foi financiado pela UFAL e teve a duração de dois anos (2011 e 2012). Atualmente estamos implantando outro; com a mesma temática voltada para os alunos do ensino médio das escolas públicas de Maceió - AL.

2 - Nome completo: Paulo Reglus Neves Freire. Nordestino, nascido em Recife, no dia 19 de setembro de 1921. Seu falecimento ocorreu em São Paulo, no dia 2 de maio de 1997. Tem uma obra extensa e politicamente/socialmente engajada. Foi exilado político durante a Ditadura Militar (1964-1985) e trabalhou em diversos países como Chile e Guiné-Bissau. É considerado um dos pensadores críticos na história da Pedagogia, com reconhecimento internacional.

3 - Disponível em http://tnh1.ne10.uol.com.br/noticia/maceio/2013/07/29/258153/alagoas-tem-o-pior-indice-dedesenvolvimento-humano-do-pais-diz-pnud. Acesso em 10 de agosto de 2013.

4 - Disponível em http://web.observatoriodasmetropoles.net/planosdiretores/produtos/al/Avaliacaomaceio.pdf. Acesso: 20 de agosto de 2013.

5 - Conferir Estatuto da UFAL, Maceió, 2006.

6 - O projeto foi renovado em 2013.

\section{REFERÊNCIAS}

ACIOLI, Adenize Costa. O poder público e a política de expansão do ensino médio em Alagoas: projeto escola jovem. Dissertação de Mestrado (Programa de Educação). Maceió, UFAL, 2003.

ALAGOAS. Universidade Federal de Alagoas. Estatuto da UFAL. Maceió, 2006.

ARENDT, Hannah. A condição humana. Trad. Roberto Raposo. Rio de Janeiro: Forense Universitária, 2008. 
BALZAC, Honoré de. Ilusões perdidas. São Paulo: Companhia das Letras, 2010.

BRASIL. Constituição Federal da República dos Estados Unidos do Brasil, 15 de novembro de 1988, Brasília.

Lei de Diretrizes e Base da Educação Nacional n. 9.394 de 20 de dezembro de 1996. Brasília, 1996.

. Comitê Nacional de Educação em Direitos Humanos. Plano Nacional de Educação em Direitos Humanos / coordenação de Herbert Borges Paes de Barros e Simone Ambros Pereira; colaboração de Luciana dos Reis Mendes Amorim [et al.]. — Brasília: Secretaria Especial dos Direitos Humanos; Ministério da Educação, 2003.

Ministério da Educação. Secretaria de Assuntos Estratégicos da Presidência da República. Reestruturação e Expansão do Ensino Médio do Brasil. (Gt Interministerial Instituído Pela Portaria Nº 1189 de 05 de dezembro de 2007 e a Portaria No 386 de 25 de Março de 2008).

. Ministério da Educação. Conselho Nacional de Educação Conselho Pleno. Resolução $n^{o}$ 1, de 30 de maio de 2012, Estabelece Diretrizes Nacionais para a Educação em Direitos Humanos.

. Ministério da Educação. Parâmetros Curriculares Nacionais para o Ensino Médio. Brasília: 1999.

CABRAL NETO, Antônio. (org). Política educacional: desafios e tendências. Porto Alegre: Sulina, 2004.

CHESNAIS, François. A Mundialização do Capital. São Paulo: Xamã, 1996.

CHONCHOL; Jacques. Prefácio. In: FREIRE, Paulo. Extensão ou comunicação? tradução de Rosisca Darcy de Oliveira. Prefácio de Jacques Chonchol. 7. ed. Rio de Janeiro, Paz e Terra, 1983.

DELORS, Jacques (Coord.). Os quatro pilares da educação. In: Educação: um tesouro a descobrir. São Paulo: Cortez, 2004.

FREIRE, Paulo. Extensão ou comunicação? tradução de Rosisca Darcy de Oliveira. Prefácio de Jacques Chonchol. 7. ed. Rio de Janeiro, Paz e Terra, 1983.

FRIGOTTO, Gaudêncio. Educação e crise do trabalho: perspectivas de final de século. Editora: Vozes, Petrópolis, 1998. 
Instituto Brasileiro de Geografia e Estatística. PNAD, 2000.

KRAWCZYK, Nora. A construção social das políticas educacionais no Brasil e na América Latina. In: KRAWCZYK, Nora; CAMPOS, Maria Malta; HADDAD, Sérgio (orgs). $O$ cenário Educacional Latino Americano no Limiar do Século XXI: Reformas em debate. São Paulo: Autores Associados; 2000.

MARTINELLI, Maria Lúcia. Notas sobre instituição. São Paulo: PUC-SP, Faculdade de Serviço Social, s/d, mimeo.

PAULO NETTO, José. Marxismo impenitente: contribuição à história das ideias marxistas. São Paulo: Cortez, 2004.

PROEX, UFAL. Projeto de Formação Continuada em Direitos Humanos para Professores do Ensino Médio. Maceió, 2011. (Digitado).

. Projeto Capacitação de educadores da rede básica de ensino em Educação em Direitos Humanos. Maceió, 2010. (Digitado).

NOGUEIRA, Maria das Dores Pimentel (org.). Extensão universitária: diretrizes conceituais e políticas. Belo Horizonte: Fórum Nacional de Pró-Reitores de Extensão das Universidades Públicas/ UFMG, 2000.

RABENHORST, Eduardo. Dignidade humana e moralidade democrática. Brasília: Brasília Jurídica, 2001.

O que são direitos humanos? In: . Educação em Direitos Humanos: fundamentos histórico-filosóficos. João Pessoa: Editora da UFPB, 2010.

SILVA, Maria Ozanira da Silva e (Coord.). A Comunidade solidária: o não enfrentamento da pobreza no Brasil. São Paulo: Cortez Editora, 2001.

THIOLLENT, Michel. A metodologia da pesquisa-ação. 15. ed. São Paulo: Cortez, 2007.

\section{RECEBIDO EM:}

APROVADO EM: 25/09/2015 